CLINICAL ETHICS

\title{
The utilitarian argument for medical confidentiality: a pilot study of patients' views
}

\section{Jones}

Correspondence to:

Dr Chris Jones, Consultant

Forensic Psychiatrist,

Norvic Clinic, St Andrew's

Business Park, Thorpe St

Andrew, Norwich

NR7 OHT, UK;

christopher.jones@

norfmhc-tr.anglox.nhs.uk

Revised version received 19 July 2002

Accepted for publication

12 December 2002
Objectives: To develop and pilot a questionnaire based assessment of the importance patients place on medical confidentiality, whether they support disclosure of confidential information to protect third parties, and whether they consider that this would impair full disclosure in medical consultations.

Design: Questionnaire administered to 30 consecutive patients attending a GP surgery.

Results: Overall patients valued confidentiality, felt that other patients might be deterred from seeking treatment if it were not guaranteed, but did not think that they would withhold information for this reason themselves.

Conclusions: When presented with brief details of five clinical situations in which a breach of confidentiality might be considered, a clear majority of subjects believed that doctors should disclose information in two of the situations, but subjects were not confident that doctors would do so. In three situations, about half felt that disclosure was justified-these included the only scenario in which disclosure was clearly mandated by statute. There was little change in patients' general attitude to confidentiality after considering the scenarios. However, the views expressed were often inconsistent with responses to the clinical scenarios, suggesting that complex opinions were not accurately reflected in the responses. The format of the questionnaire has been amended, and the study will be repeated with other groups of patients.
C onfidentiality is a central feature of all statements of ethical medical practice. ${ }^{1}$ The General Medical Council and other professional bodies stipulate confidentiality as an ethical obligation, but also allow breaches of confidentiality in certain circumstances, for example in order to protect third parties from possible harm. ${ }^{2}$

Most discussions of this issue take a utilitarian view. ${ }^{13}$ It is argued that confidentiality must be guaranteed if patients are to speak freely and frankly to doctors, so that appropriate diagnosis and treatment can be given. If so, then failure to guarantee confidentiality will lead to non-presentation, misdiagnosis, or failure of treatment, and ultimately cause more harm than maintaining confidentiality. Legal precedents have also adopted utilitarian arguments. ${ }^{4}$

The utilitarian justification for maintaining medical confidentiality rests ultimately on a calculation of the effects of confidentiality or disclosure on the behaviour of current and potential future patients. This calculation is often based upon theoretical views of how patients are likely to behave, but in principle it is also open to empirical study: how does the behaviour of patients alter when presented with different standards of confidentiality? Only if there is good reason, grounded in empirical evidence, to believe that patients will be reluctant to disclose potential damaging information in situations where subsequent disclosure is anticipated, could we be confident that the utilitarian basis for confidentiality is justified. Conversely, evidence that patient behaviour is not significantly altered by disclosure practices would fundamentally weaken the utilitarian position.

Surprisingly, such empirical evidence is not readily available, perhaps because ethical questions are commonly considered to be better answered by appeal to theory rather than by practical testing. It is usually assumed that patients consider confidentiality to be important and that they would be less likely to seek treatment if this was not assured ${ }^{6}$; few studies have asked patients directly. This study represents a preliminary attempt to assess the views of patients on this issue.
There are other arguments in favour of maintaining confidentiality. It can be seen as enhancing autonomy, as it gives the patient control over his or her personal information; as a form of property right, in which information "belongs to" the patient, who may therefore control its use; or as arising from agreement, so that a doctor may be obliged to honour the undertaking (explicit or implied) to maintain confidentiality. These arguments might justify confidentiality even if the utilitarian argument was undermined, but are beyond the scope of this paper.

Decisions about confidentiality, particularly where disclosure is to be justified in terms of reducing risk to a third party, are strongly influenced by considerations of public policy. Both legal precedents and quasi-legal standards such as codes of practice and professional guidance are usually justified, explicitly or implicitly, in terms of a utilitarian calculus; that disclosure in certain circumstances is justified because overall greater benefit will result than there would be from maintaining confidentiality. Again, this utilitarian calculus is one that, in part, can be supported or undermined by an empirical enquiry into the views and behaviour of patients. There are perhaps few areas in which primary research would be so directly relevant to issues of general policy.

A utilitarian calculus is also involved in situations where disclosure of confidential information is contemplated in order to protect a third party from harm. Is the direct detriment to the patient, and the potential future effect on other patients, outweighed by the benefit of preventing harm to the anticipated victim? How might this calculation be affected by the likelihood or severity of the expected harm, the number of potential victims, and whether or not a specific victim can be identified?

In a BMA survey $93 \%$ of respondents (members of the general public) agreed with a statement that "doctors are patients' representatives and therefore should not be expected to release information about a patient to a third 
party without the patient's properly informed consent" ${ }^{\prime 8}$ This seems to show a very high level of public support for an absolute standard of confidentiality; however respondents were not presented with examples of circumstances in which disclosure might be made, and arguably the phrasing of the question lacks clarity and may tend to invite a positive response, without adequately reflecting a complex judgement.

Knowles and McMahon found that members of the public supported breaching confidentiality when a client reported murder (planned or confessed), suicide plans, child abuse, or treason. ${ }^{9}$ In an experimental setting, undergraduates who were promised confidentiality during an interview were more likely to reveal personal information than those who were not. ${ }^{10}$

Schmid et al found that psychiatric patients valued confidentiality highly and were concerned about the possibility of unauthorised disclosures. ${ }^{11}$ Two thirds said they would become angry or threaten to leave treatment if information were released without permission. Holahan and Slaikeu studied patients receiving psychotherapy, and concluded that fears of a loss of confidentiality could be devastating to their treatment. ${ }^{12}$ A similar study concluded that almost all patients would prefer to be told about the limitations of confidentiality before commencing treatment, but that when informed may choose to limit their therapeutic communications, thus impairing treatment. ${ }^{13}$ Van de Creek et al found that clients' views about appropriate disclosure varied, but that confidentiality was widely expected. ${ }^{14}$

Lindenthal and Thomas found that, although $22 \%$ of psychiatric patients and 33\% of non-patients expressed a reluctance to share certain information because of concerns about confidentiality, psychiatrists were less likely to disclose than patients anticipated. ${ }^{15}$ They concluded "the fear that a psychiatrist might disclose confidences may sometimes be an important impediment to obtaining psychiatric care" (Lindenthal and Thomas, ${ }^{15}$ p321). Mechanic and Meyer explored various factors contributing to patients' trust in doctors. ${ }^{16}$ Psychiatric patients expressed significantly more concerns about confidentiality than did patients with physical illness.

\section{STUDY AIMS}

To develop and pilot a self administered questionnaire, which could be used to explore the views of patients in different settings with respect to:

- The importance of medical confidentiality

- Situations in which patients consider confidentiality should be breached

- Whether patients are confident that doctors would act as patients believe they should

- Whether compromising confidentiality would deter patients from seeking treatment.

\section{METHODS}

A questionnaire was designed for use in this pilot study. The questionnaire started with 12 questions about general attitudes to the issues, six to be answered yes, no, or unsure, and six to be answered on a five point scale, (strongly agree, agree, don't know, disagree, strongly disagree). Because of the small number of subjects recruited for this pilot study, responses to the second six questions have been combined into three categories (agree, don't know, disagree) for analysis. The question asked in the BMA survey ${ }^{8}$ was repeated, despite some misgivings about the wording, to allow a direct comparison to be made.
Box 1 Confidentiality scenarios

1. A man goes to see his doctor because he has blackouts. The doctor thinks he is suffering from epilepsy. The man does a lot of driving in his job, and doesn't want to lose his driving licence. Should the doctor tell the DVLA?

2. A man goes to the "special clinic" because he has a sexually transmitted disease ("VD"). The doctor wants him to tell his wife, so that she can have a check up, but he doesn't want her to know. Should the doctor tell the wife?

3. A woman has been seeing her doctor for some time because she is mentally ill. She tells the doctor that her neighbour is persecuting her, and that she is going to kill him. Should the doctor tell the police?

4. A man tells his doctor that he has been sexually abusing his daughter. He wants help but doesn't want anybody else to know. Should the doctor tell social services?

5. A man is seen for treatment in accident and emergency after crashing his car. The doctor suspects he has been drinking alcohol. Should the doctor tell the police?

This was followed by five brief scenarios giving rise to dilemmas related to confidentiality. Each scenario was followed by questions to establish whether subjects thought that confidentiality should be breached, how they believed doctors would behave, and whether disclosure would deter patients from seeking treatment. In two scenarios, subjects were asked whether the doctor should disclose information to an official agency (police or social services) and, separately, whether the doctor should disclose directly to a person at risk. There was an opportunity for subjects to give more detailed explanations of their responses if they wished. Following the last scenario, the six questions about general attitudes were repeated. Of the subjects, 10 completed an alternative version of the questionnaire, which was identical except for the addition of a sixth scenario. One scenario, which did not relate to a potential risk to others, has been excluded from analysis. The other five scenarios are listed in box 1 .

Scenarios were chosen to which differing levels of legal/ professional obligations would apply. Only in scenario five (drink driving) is there a clear and unambiguous legal duty to disclose. ${ }^{17}{ }^{18}$ In two further scenarios (child sexual abuse; driver with epilepsy) there is formal guidance that would support or require disclosure. ${ }^{1920}$ In the two remaining scenarios no clear guidance exists; issues of risk and public protection relating to the mentally ill seem to have a high media profile, possibly reflecting public concern.

The study was conducted on consecutive male and female patients aged over 16 attending appointments with their GPs at a morning surgery in a small town in North Wales. This population was chosen for study as representing a general clinical population, for whom issues of medical confidentiality would have some relevance, but for whom the specific dilemmas raised by the scenarios would be unlikely to have personal significance. Each subject was verbally briefed about the purpose of the study and assurances of anonymity provided. The questionnaire was then completed by the subject without further assistance. No identifying demographic information, such as age or gender, was collected. In view of the small number of subjects included in this pilot study, and the possibility of spurious significance resulting 
from multiple comparisons, no statistical analysis of the data has been presented. The results have been used to inform the development of future studies.

The study design received ethical approval from the North West Wales Research Ethics Committee.

\section{RESULTS}

A total of 30 subjects were included in the study. All patients who were approached agreed to participate. One subject withdrew before completing all of the sections, when called for their appointment. The remaining 29 subjects were asked a total of 1015 questions; only nine answers were missing from the completed questionnaires.

Although confidentiality was clearly valued, subjects gave contradictory responses to the general questions (tables 1 and 2). All 30 agreed with the statement that they expected confidentiality from their doctor, although only $72 \%(21 / 29)$ were confident that this would be provided. Eighty-three percent $(25 / 30)$ agreed that confidentiality should be maintained without exception, and $80 \%(24 / 30)$ agreed with a statement that information should not be released without the patient's consent. However, 37\% (11/30) also agreed that there were times when it was acceptable for their doctor to disclose confidential information without permission, and $77 \%(23 / 30)$ agreed that confidentiality should be broken when other people were placed at risk. The nature of the study did not allow these contradictions to be explored with individual subjects.

The view that confidentiality should be maintained without exception was less strongly supported after the scenarios had been considered; $80 \%$ (25/30) agreed initially, compared with $69 \%(20 / 29)$ at the end. There were no apparent changes in other views.

In general there was support for disclosure of confidential information in the scenarios presented (table 3). Across the five scenarios $63 \%$ (77/123) supported disclosure, ranging from $86 \%(25 / 29)$ in the case of child abuse to $50 \%(15 / 30)$ in the case of sexually transmitted disease.

One question was ambiguously worded; it was therefore not possible to determine how subjects believed the doctor would behave in the child sexual abuse scenario, which is omitted from the discussion in this paragraph. Of 52 responses (across all scenarios) in which subjects indicated that the doctor should disclose, only 20 subjects (38\%) were confident that disclosure would be made and 12 (23\%) believed that the doctor would not disclose. Of 25 responses that disclosure should not be made, $16(64 \%)$ believed that the doctor would not disclose and five $(20 \%)$ believed that the doctor would disclose. Overall, only $47 \%$ of responses indicated confidence that doctors would act in the way subjects believed that they should, with a greater concern about under-disclosure than over-disclosure.

In two scenarios (child sexual abuse and mental illness: threat to neighbour) subjects were asked whether the doctor should disclose to an appropriate authority (social services, police) and to others (wife, neighbour). In both cases there was greater support for disclosure to the authorities (25/29 $(86 \%)$ and $14 / 27(52 \%))$ than there was for disclosure to others $(14 / 29(48 \%)$ and $7 / 29(24 \%))$.

In each scenario, subjects were asked whether they thought that patients in the situation would be less likely to seek medical help, if they were aware that information might be disclosed by the doctor. It was widely recognised that concerns about confidentiality might discourage patients from seeking treatment (table 4). However the two scenarios in which this was perceived as most likely (child sexual abuse and driver with epilepsy) were also the two for which breach of confidence was most strongly supported. Overall subjects were confident that treatment would not be affected in only $20 \%(25 / 125)$ of responses.

In this study, six subjects $(20 \%)$ indicated that they would be reluctant to reveal certain information to their doctor because of concerns about confidentiality. Combining their views from the five scenarios, two interesting differences emerge.

Subjects concerned for their own confidentiality were less likely to support disclosure across the range of scenarios than subjects who were not concerned (11/24 (46\%) v 66/99 $(67 \%))$. They were also more likely to believe that future treatment might be impaired (18/25 (72\%) v 59/101 (58\%)).

\section{DISCUSSION}

Some significant limitations of this pilot study mean that caution has to be exercised in drawing conclusions from the results. The number of subjects reported is low, the questionnaire has not been validated, and the wording of some questions was considered ambiguous. Despite these caveats, some initial observations can be made, and hypotheses generated for further investigation.

Patients in this pilot study appear to have complex views about confidentiality. A large majority endorsed both "confidentiality without exception" and "no disclosure without informed consent". Despite clear support for disclosure in the scenarios presented, subjects maintained these positions. Future studies should beware of relying upon responses to apparently straightforward statements as accurately reflecting complex points of view.

At first sight, subjects' responses to the general statements might seem to give very clear support for confidentiality, as was concluded in the BMA survey. ${ }^{8}$ However in their responses to the scenarios it is clear that subjects' views are actually much more complex, and that medical confidentiality does not have unqualified support in this population.

There was consistent support for confidentiality in medical consultations, and recognition that failure to guarantee confidentiality might deter patients from seeking treatment. This might seem to support the utilitarian value of confidentiality, but even recognising the risk of impairing treatment seems to leave many subjects unconvinced of the importance of non-disclosure. A preliminary conclusion

\begin{tabular}{lcccl}
\hline Table 1 General questions: subjects' attitudes towards their own confidentiality \\
\hline & Yes & No & Unsure \\
\hline $\begin{array}{l}\text { Do you expect things you discuss with your doctor to be kept confidential? } \\
\text { Do you think the doctor would ever tell other people about your case }\end{array}$ & 30 & 0 & 0 \\
without your permission? & 3 & 21 & 5 \\
$\begin{array}{l}\text { Are there any times when it is acceptable for the doctor to discuss your } \\
\text { case with other people without your permission? }\end{array}$ & 11 & 14 & 5 \\
$\begin{array}{l}\text { Is there anything which you would not tell your doctor because they } \\
\text { might tell someone else? }\end{array}$ & 6 & 22 & 2 \\
$\begin{array}{l}\text { In the past has your doctor ever discussed confidentiality with you? } \\
\text { Would you want to be informed of the exceptions to confidentiality? }\end{array}$ & 5 & 25 & 3 & 2 \\
\hline
\end{tabular}


Table 2 General questions: attitude to confidentiality before and after considering scenarios

\begin{tabular}{|c|c|c|c|c|}
\hline \multicolumn{2}{|l|}{ Statement } & \multirow{2}{*}{$\begin{array}{l}\text { Agree } \\
25\end{array}$} & \multirow{2}{*}{$\begin{array}{l}\text { Unsure } \\
2\end{array}$} & \multirow{2}{*}{$\frac{\text { Disagree }}{3}$} \\
\hline Confidentiality should be maintained between a doctor and & Before & & & \\
\hline patient at all times without exception. & After & 20 & 3 & 6 \\
\hline Confidentiality should be broken if a client discloses & Before & 23 & 5 & 2 \\
\hline $\begin{array}{l}\text { information that places the patient at risk of injury/harm/ } \\
\text { illness. }\end{array}$ & After & 23 & 3 & 3 \\
\hline Confidentiality does not affect the patient in any way and & Before & 0 & 3 & 27 \\
\hline $\begin{array}{l}\text { therefore it doesn't really matter if the doctor discusses } \\
\text { information with others. }\end{array}$ & After & 1 & 3 & 25 \\
\hline A doctor should always ask permission from or inform the & Before & 28 & 1 & 1 \\
\hline patient before he or she breaks confidentiality. & After & 25 & 3 & 1 \\
\hline Confidentiality should be maintained whenever possible with & Before & 27 & 3 & 0 \\
\hline $\begin{array}{l}\text { the exception of situations where there is a risk of harm to } \\
\text { others. }\end{array}$ & After & 26 & 1 & 0 \\
\hline Doctors are patients' representatives and therefore should & Before & 24 & 3 & 3 \\
\hline $\begin{array}{l}\text { not be expected to release information about a patient to a } \\
\text { third party without the patient's properly informed consent. }\end{array}$ & After & 23 & 3 & 3 \\
\hline
\end{tabular}

might be that, faced with difficult dilemmas of this sort, greater value is placed on immediate protection of a third party than on the longer term promotion of effective medical treatment. Balancing such interests is always difficult, and faced with an immediate quantifiable risk, compared with a more speculative and longer term impairment of future treatments, a decision to breach confidentiality in an isolated case might be supported, perhaps without giving full weight to the potential consequences in many other cases. If so, this would imply that decisions about disclosure would be better made in principle before a dilemma arises, rather than being determined only when faced with a specific clinical situation. It is likely to be relevant here that most subjects in this study did not report concerns about their own confidentiality. Patients for whom the issues were more directly relevant (for example, attendees at a sexually transmitted disease or psychiatric clinic) might have different views.

There was a high degree of support for disclosure to protect third parties. This was highest in the situations involving child sexual abuse and driving, where guidance is already issued to the profession, suggesting that such guidance would have the support of public opinion. However support was lower in the only situation where a statutory duty to disclose applied. This may reflect current levels of public concern over issues such as child sexual abuse. Alternatively, the scenario relating to drink driving may be closer to subjects' own experience, which may lead some people to take a different approach, recognising that this may impact more directly on their own situation. There was recognition that disclosure might deter some patients from seeking treatment, but generally this seems to be accepted as a price worth paying. It is not clear whether or not subjects engaged in any balancing of the risks and benefits involved, and a more sophisticated study might encourage subjects to balance prevention of immediate harm with longer term increased risk.

Table 3 Should the doctor disclose without consent?

\begin{tabular}{lcll}
\hline Scenario & $\begin{array}{l}\text { Yes } \\
\text { n (\%) }\end{array}$ & $\begin{array}{l}\text { No } \\
\text { n (\%) }\end{array}$ & $\begin{array}{l}\text { Unsure } \\
\text { n (\%) }\end{array}$ \\
\hline Child sexual abuse* & $25 / 29(86)$ & $2 / 29(7)$ & $2 / 29(7)$ \\
Driver with epilepsy & $18 / 28(64)$ & $8 / 28(29)$ & $2 / 28(7)$ \\
Drink driving & $5 / 9(55)$ & $1 / 9(11)$ & $3 / 9(33)$ \\
Mental illness: threat to & $14 / 27(52)$ & $5 / 27(19)$ & $8 / 27(30)$ \\
neighbour* & & & \\
Sexually transmitted disease & $15 / 30(50)$ & $11 / 30(37)$ & $4 / 30(13)$
\end{tabular}

*Results refer to disclosure to police and/or social services.
Although subjects trusted doctors with their own confidential information, they were not sure that doctors "would" act in the way subjects believed they "should". This was true both in situations where subjects supported disclosure and where they opposed it, but more so in the former than the latter. Very few subjects indicated that they would not value discussion of confidentiality issues with their doctor: there may be an opportunity for doctors to develop public confidence by raising these issues with patients explicitly.

Where two forms of disclosure were offered, subjects were more in favour of disclosure to appropriate authorities than to potential victims. This is in line with current professional practice and guidelines.

The utilitarian position receives considerable support from the views expressed in this study by patients. They clearly value confidentiality, see it as important in a medical consultation, and recognise that disclosure without consent would be likely to deter some patients from seeking treatment. To this extent it seems that the generally accepted view of the benefits of confidentiality can be justified. However for many people the utility of confidentiality appears to be outweighed by the benefits of disclosure in order to protect third parties. They were prepared to endorse disclosure of information at the same time as recognising that treatment might be impaired as a result. Subjects with pre-existing concerns about their own confidentiality were less likely to support disclosure and more likely to anticipate impairment of effective treatment. It may be that other subjects underestimated the likely impact of disclosure on patients directly affected: future work could usefully compare such patients with general patient or non-patient populations.

Table 4 Would a patient with this problem be less likely to consult a doctor if they thought the doctor might tell others without their permission?

\begin{tabular}{lcll}
\hline Scenario & $\begin{array}{l}\text { Yes } \\
\text { n (\%) }\end{array}$ & $\begin{array}{l}\text { No } \\
\text { n (\%) }\end{array}$ & $\begin{array}{l}\text { Unsure } \\
\text { n (\%) }\end{array}$ \\
\hline Child sexual abuse & $22 / 29(76)$ & $1 / 29(3)$ & $6 / 29(21)$ \\
$\begin{array}{l}\text { Driver with epilepsy } \\
\text { Drink driving }\end{array}$ & $23 / 30(77)$ & $4 / 30(13)$ & $3 / 30(10)$ \\
$\begin{array}{l}\text { Mental illness: threat to } \\
\text { neighbour }\end{array}$ & $14 / 9(56)$ & $2 / 9(22)$ & $2 / 9(22)$ \\
Sexually transmitted disease & $13 / 29(45)$ & $9 / 29(31)$ & $6 / 29(21)$ \\
\hline
\end{tabular}


Despite the limited nature of this pilot study it does suggest that there would be value in a larger scale study. Working hypotheses that could be tested include:

- Patients generally recognise that breaches of confidentiality may deter patients from seeking further treatment, but none the less, many patients will support disclosure to protect third parties

- Patients' expectations about disclosure will vary depending on the nature of the risk involved

- Patients who are concerned for their own confidentiality will be less likely to support disclosure in hypothetical situations

- Patients in health care settings where disclosure is potentially particularly damaging will value confidentiality more highly.

Future work in this area will need to recognise the very complex attitudes and beliefs held by patients. A particular area of interest would be the balance to be struck between the long term good of providing effective medical treatment and the short term good of protecting a third party.

This pilot study has identified several problems with the questionnaire, and amendments will be made before further work is done. The closed nature of questions in a questionnaire format does not seem to allow subjects adequately to express complex views, and an interview based approach may prove more useful. However, it is possible that some subjects might feel more able to give honest responses when protected by the anonymity of a questionnaire. Collecting demographic information such as age and gender would add an interesting dimension to analysis of future results, but subjects might be deterred from participating unless care is taken that none of this information could identify an individual. Depending on the setting and the number of potential subjects, even general demographic information might be identifiable. This is potentially a particular issue for subjects who have pre-existing concerns about their own confidentiality, whose views are of particular relevance to the utilitarian hypothesis.

\section{ACKNOWLEDGEMENTS}

I am very grateful to Ms Ann-Marie Taylor, formerly Research Assistant with the North Wales Forensic Psychiatric Service, who played a significant part in developing the questionnaire and in collecting the data for this study. However the opinions expressed in this paper are solely the responsibility of its author.

\section{What this paper adds}

- It is commonly assumed that patients expect confidentiality from their doctors, and would be less likely to reveal information that might be detrimental to them if they were not confident that secrets would be kept. This view (the utilitarian hypothesis) is used to justify the need for medical confidentiality, but few studies have explored patients' views.

- Although patients strongly endorsed confidentiality, they also supported disclosure in most situations in which third parties were at risk, despite recognition that this would impair effective medical treatment.

\section{REFERENCES}

1 BMA. Confidentiality and disclosure of health information. London: BMA 1999.

2 General Medical Council. Confidentiality: protecting and providing information. London: GMC, 2000.

3 Thompson IE. The nature of confidentiality. J Med Ethics 1979;5:57-64.

$4 \mathrm{~W} \vee$ Egdell [1990] 1 All ER 835

$5 \mathrm{X} \vee \mathrm{Y}$ [1988] 2 All ER 648.

6 Havard J. Medical confidence. J Med Ethics 1985;11:8-11

7 Lee R. Deathly silence: doctors' duty to disclose dangers of death. In: Lee R, Morgan D, eds. Death rites: law and ethics at the end of life. London: Routledge, 1994:279-302.

8 Hallows N, Ryan C, Scott G, et al. A love-hate relationship? BMA News Review April 1998:17.

9 Knowles A, McMahon M. Expectations and preferences regarding confidentiality in the psychologist-client relationship. Aust Psychol 1995;30:175-8.

10 Woods KM, McNamara JR. Confidentiality: its effect on interviewee behaviour. Prof Psychol 1980;11:714-21.

11 Schmid D, Appelbaum P, Roth LH, et al. Confidentiality in psychiatry: a study of the patient's view. Hosp Community Psychiatry 1983;34:353-5.

12 Holahan CJ, Slaikeu KA. Effects of contrasting degrees of privacy on client self-disclosure in a counselling setting. J Couns Psychol 1977;24:55-9.

13 Miller DJ, Thelen MH. Knowledge and beliefs about confidentiality in psychotherapy. Prof Psychol Res Pr 1986;17:15-19.

14 Van de Creek L, Miars RD, Herzog CE. Client anticipations and preferences for confidentiality of records. J Couns Psychol 1987;34:62-7.

15 Lindenthal JJ, Thomas CS. Psychiatrists, the public and confidentiality. J Nerv Ment Dis 1982;170:319-23.

16 Mechanic D, Meyer S. Concepts of trust among patients with serious illness. Soc Sci Med 2000;51:657-68.

17 Section 172(2)(b), Road Traffic Act 1988. London: HMSO, 1988.

18 Hunter v Mann [1974] 1 QB 767.

19 Department of Health. Child protection: medical responsibilities. London: HMSO, 1996.

20 Driver and Vehicle Licensing Authority. At a glance guide to the current medical standards of fitness to drive. Swansea: DVLA, 1999. 